
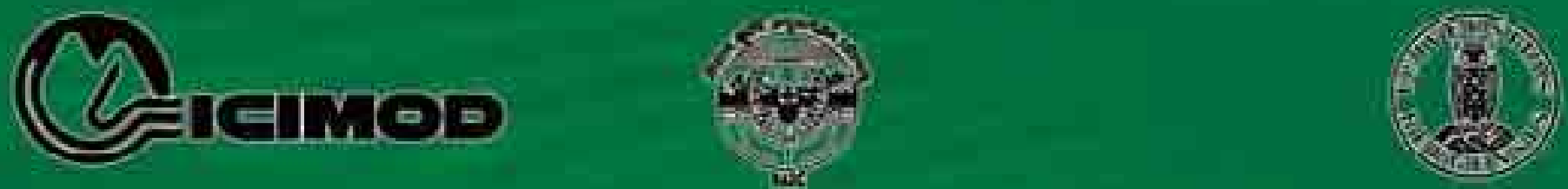

\title{
Micronutrients in South and South East Asia
}

Proceedlings of an International Workshop held 8.11 September, 2004, Kathimandu, Nepal

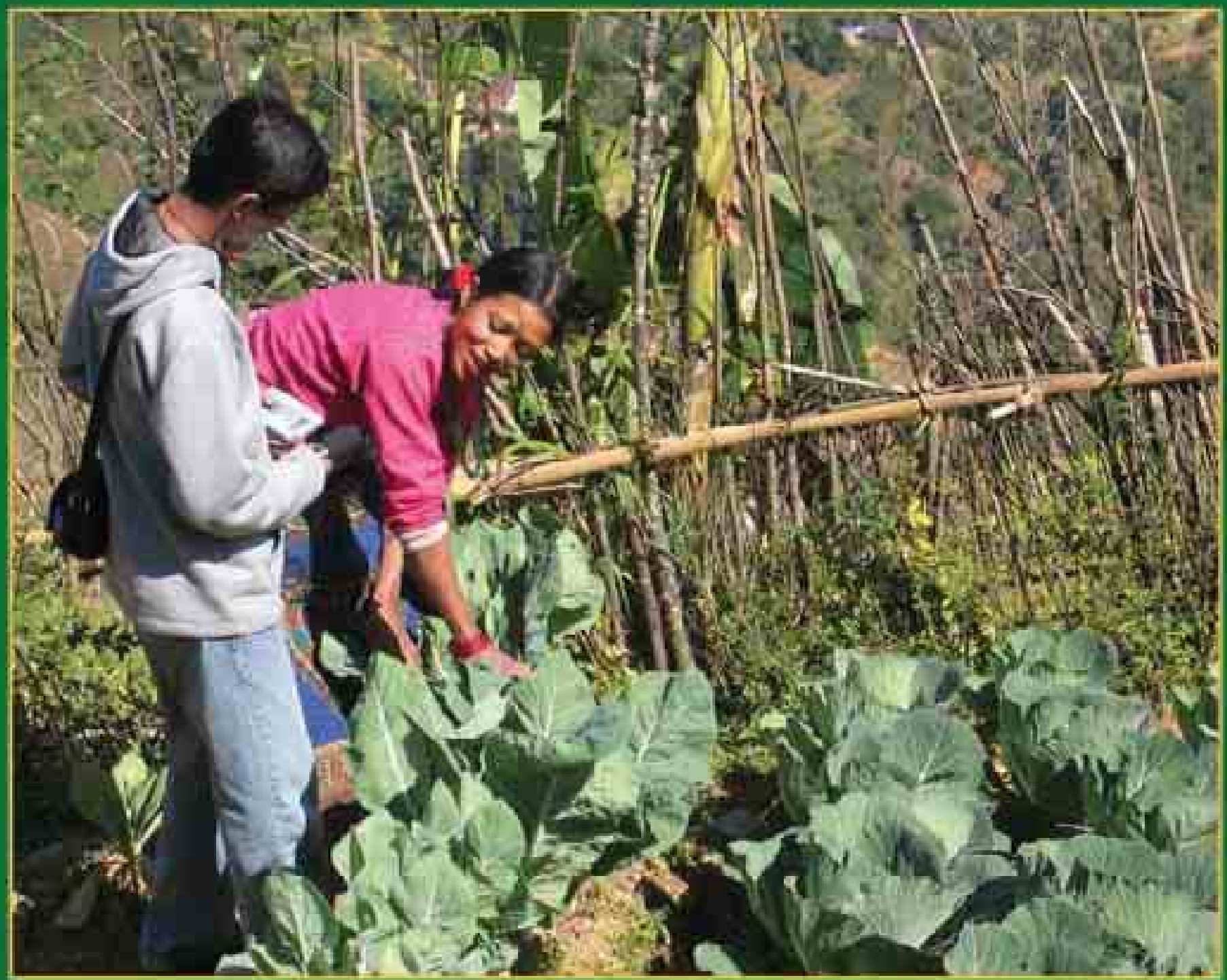

Editors

Peter Andersen, Junoo K. Tuladhar, Krishna B. Karki, and Surya L. Maskey 


\section{About the Organisations}

The International Centre for Integrated Mountain Development (ICIMOD) is an independent 'Mountain Learning and Knowledge Centre' serving the eight countries of the Hindu Kush-Himalayas - Afghanistan - Bangladesh - Bhutan - China

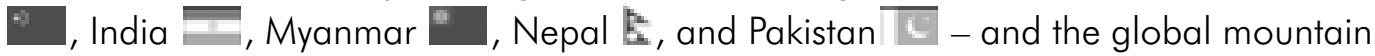
community. Founded in 1983, ICIMOD is based in Kathmandu, Nepal, and brings together a partnership of regional member countries, partner institutions, and donors with a commitment for development action to secure a better future for the people and environment of the Hindu Kush-Himalayas. ICIMOD's activities are supported by its core programme donors: the Governments of Austria, Denmark, Germany, Netherlands, Norway, Switzerland, and its regional member countries, along with over thirty project co-financing donors. The primary objective of the Centre is to promote the development of an economically and environmentally sound mountain ecosystem and to improve the living standards of mountain populations.

The Nepal Agricultural Research Council (NARC) was established in 1991 as an autonomous research organisation under the Nepal Agricultural Research Act of HMG/Nepal. The major objective of NARC is to uplift the socioeconomic level of the Nepalese people by developing and disseminating technologies that increase the productivity and sustainability of resources devoted to agriculture. NARC research programmes are carried out at four regional research stations, 16 commodities research programmes, and 17 agricultural research stations located at different places representing different agro-ecological regions all over the country.

The University of Bergen (UoB) is Norway's second largest university. The university is located on the North Sea coast; marine research is one of the major focus points, but interdisciplinary development research is another long term commitment. UoB is involved in a number of research projects in the South Asian region, including agriculture and human nutrition and development. 


\title{
Micronutrients in South and South East Asia
}

Proceedings of an International Workshop held 8-11 September, 2004, Kathmandu, Nepal

\author{
Editors \\ Peter Andersen \\ Junoo K. Tuladhar \\ Krishna B. Karki \\ Surya L. Maskey
}

International Centre for Integrated Mountain Development

Kathmandu, Nepal

Soil Science Division, Nepal Agricultural Research Council

HMGN, Kathmandu, Nepal

and

University of Bergen, Norway

December 2005 


\section{Copyright $(\odot) 2005$}

International Centre for Integrated Mountain Development

Nepal Agricultural Research Council

University of Bergen

All rights reserved

\section{ISBN 9291152102}

\section{Cover photos}

Front - growing vegetables in the Phulchowki watershed, Nepal, Ujol Sherchan

Background - rice terraces in Nepal, ICIMOD File photo

\section{Published by}

International Centre for Integrated Mountain Development

G.P.O. Box 3226

Kathmandu, Nepal

\section{Editorial Team}

Greta Mary Pennington Rana (Consultant Editor)
A. Beatrice Murray (Senior Editor)
Dharma R. Maharjan (Technical Support and Layout Design)

\section{Printed and bound in Nepal by}

Quality Printers (P) (Pvt.)

Kathmandu, Nepal

The views and interpretations in this publication are those of the authors. They are not attributable to the International Centre for Integrated Mountain Development (ICIMOD), His Majesty's Government of Nepal or the University of Bergen, Norway, and do not imply the expression of any opinion concerning the legal status of any country, territory, city or area of its authorities, or concerning the delimitation of its frontiers or boundaries, or the endorsement of any products. 


\section{Foreword}

Plant nutrients are essential for producing sufficient and healthy food for the world's expanding population, especially in South and South East Asia. Unbalanced use of mineral fertilisers and a decrease in the use of organic manure are the main causes of nutrient deficiency in this region. Moreover, agricultural intensification requires an increased flow of plant nutrients to crops and greater uptake of those nutrients by crops. Until now, micronutrients have mostly been addressed as a soil problem. But micronutrient deficiency complexities have now been observed abundantly in crops produced from micronutrient deficient soils; and these in turn produce nutrient deficient food. People depending on these foods then also display deficiency symptoms (malnutrition and certain inborn deformities in human beings). With this recognition of the importance of soil micronutrients for human well-being, the time has come to focus on a multidisciplinary and integrated approach to addressing the micronutrient problem.

The Soil Science Division of the Nepal Agricultural Research Council and the University of Bergen, Norway, organised a workshop on 'Micronutrients in South and South East Asia' in Kathmandu from 8th-10th September 2004. This was the first time in Nepal that experts in health, nutrition, plant nutrition, soil science, and other agricultural sciences had gathered together to discuss the micronutrient problem and to find a common solution for the benefit of the poorer areas of the world. The survey and research results showed widespread deficiencies of micronutrients in soils of South Asia, and also recommended some measures to correct them. Bio-fortification - breeding of varieties efficient in concentrating micronutrients from deficient soils - is one strategy. Other interesting agricultural strategies include use of improved fertilisers, seed priming with micronutrients, seedbed preparation, and improved compost management. Improved food preparation, food fortification and promotion of more nutritious food are other promising strategies. However, the problem is complex and any strategy must be evaluated in relation to the local context.

This workshop provided an international arena for micronutrient research using an integrated approach, and provided a valuable platform for sharing ideas and experiences related to addressing micronutrient problems in soil, plants, and humans. With this publication, we hope to share this knowledge with a wider audience, particularly with the many people concerned with soils, agriculture, and human nutrition in developing countries across the world, and thus to stimulate further integrated activities towards a long-term solution of micronutrient problems.

\author{
Peter Andersen \\ Associate Professor \\ University of Bergen \\ Norway
}

Surya L. Maskey

Director, Crops and Horticulture

Nepal Agricultural Research Council
J. Gabriel Campbell

Director General

ICIMOD 


\section{Editor's Preface}

This book is the proceedings of a workshop on micronutrient related research which was held in Kathmandu from 8-10 September 2004. The idea for the workshop was developed by Junoo K. Tuladhar, Krishna Karki, and Surya Maskey of the Soil Science Division of the Nepal Agricultural Research Council, and Peter Andersen of the Department of Geography, University of Bergen, Norway. The purpose was to establish the status of current knowledge and identify future research needs related to micronutrients in South and South East Asia. The main focus of the meeting was on agricultural strategies, but the participation of researchers concerned with human nutrition and other disciplines beyond plant-soil interactions served to make the workshop a truly interdisciplinary event. The participants covered a broad range of themes which together illuminate a comprehensive picture of the complexities of micronutrient issues, ranging from soil processes through plant nutrition to agricultural extension, fertiliser quality control, and the effects on human nutrition.

Several of the papers are based on relatively small collections of data or field plots, and clearly more research is needed to raise some statements from the status of 'indicative' to more strictly verified. However, the scale of the problems in agricultural productivity and human nutrition is beyond doubt. The majority of agricultural land in South Asia is severely affected by one or more micronutrient imbalances, and the majority of people in the region are suffering from micronutrient deficiencies. Insufficient supplies of iodine, iron, zinc, and vitamin A have adversely affected the health of literally hundreds of millions of people.

It is important to raise micronutrient problems much higher on the agenda, not only in terms of scientific research, but also in terms of public awareness. Agricultural research is much needed, but must be complemented with interdisciplinary research and development. There is a need to develop enabling strategies that can help farmers to carry out their own experiments and improve their soil management, as well as help people improve their own nutrition. The editors believe and hope that the quality of the papers contained in this publication can help to get research and development in the field moving ahead. The workshop was sponsored by grants from the University of Bergen, the International Centre for Integrated Mountain Development (ICIMOD), and Hill Agriculture Research Project (HARP), and ICIMOD kindly offered to publish the proceedings.

The workshop was not unaffected by the security problems and political unrest that have affected Nepal in recent years. Two keynote speakers had to cancel their participation as a result of travel restrictions imposed by their home countries. Nevertheless, the workshop was attended by some 55 researchers from 9 different countries, and several initiatives developed since it was held have shown that the undertaking was worthwhile.

It is the sincere hope of the organisers that the content of this book will provide a humble contribution to improving the livelihoods and wellbeing of the people in this region. 


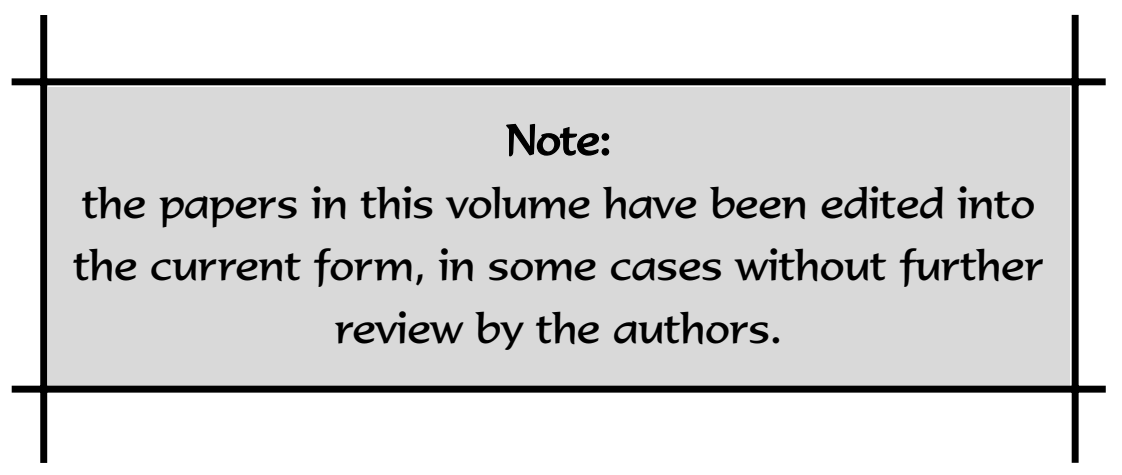




\section{Acknowledgements}

The 'International Workshop on Micronutrients in South and South-East Asia' was organised jointly by the University of Bergen (UoB) and Nepal Agricultural Research Council (NARC). The workshop was funded by UoB, for which the organising committee would like to express its sincere thanks; without this support the workshop would not have been possible. Funding from ICIMOD for two candidates from the Himalayan region to attend the workshop is gratefully acknowledged and logistics support of Hill Agriculture Research Project (HARP) also acknowledged. The organising committee thanks Professor Dr. Ross Welch for his very important Key Note speech. Likewise, although Professor Rosalind Gibson of the University of Otago in New Zealand was unable to attend the workshop in person, the paper that she sent for the workshop considerably extended the participants' knowledge on human nutrition and was sincerely appreciated. Thanks are also extended to the participants whose active participation and sharing of knowledge and experience with fellow participants helped to make the workshop such a success. The help and cooperation rendered by the staff of the Soil Science Division (NARC) is gratefully acknowledged. Many thanks are also expressed to the Mountain Hotel for its warm hospitality. Finally, the organisers wish to thank the publishing unit at ICIMOD for their kind and professional contribution in turning the proceedings of the workshop into the present publication. 


\section{Executive Summary}

A workshop on 'Micronutrients in South and South East Asia' was held in Kathmandu from 8th - 10th September 2004. Fifty-five scientists from nine countries discussed problems related to micronutrient disorders in human nutrition and agriculture, and strategies and methods to address the issues. These problems are more common in South and South East Asia than in any other region in the world owing to poverty, plant-based diets with low micronutrient density and availability, and widespread soil deficiencies.

\section{Keynote presentations}

Professor Rosalind Gibson from Otago University, New Zealand, explained that the prevalence of protein deficiency in a number of poor countries is very small compared to deficiencies of iron and zinc. The adverse effects of a poor supply of iron, zinc, iodine, selenium, vitamin $A$, and vitamin $B_{12}$ include productivity, cognition, morbidity, and mortality, in other words not only human health, but also socioeconomic conditions at large. A case study by Gibson showed the potential impact of food processing at local level, including soaking and fermentation of cereals in order to increase bioavailability of micronutrients, increased intake of locally available foods with higher content of micronutrients, and nutrient rich porridges for child feeding. The study showed that changing cooking processes and local diets has a potential to increase the nutritive value significantly, but not enough to bring all people out of a deficient status. Therefore, dietary interventions should be supplemented with other strategies encompassing a larger part of the food system, for example food fortification and bio-fortification.

Professor Ross Welch from Cornell University, USA, addressed the connection between farming systems and food systems. Between 1965 and 1999, there was a dramatic decrease in the density of micronutrients in the diets of the average population in developing nations in general, and in South Asia in particular. One important reason was the change in balance between population, cereal production, and pulse production. Whereas the increase in cereal production was bigger than the population growth, the per capita availability of pulses - the nutrient rich part of the diets - declined to less than half as a result of deficiencies of boron, zinc, and molybdenum. This in turn effects the provision of iron and zinc in human diets, and in particular among people with rice-pulse based diets. Welch proposed a number of different strategies to make agriculture more sustainable in terms of provision of healthy food to people including improved fertilisation, promotion of crops with higher nutrient density and availability, breeding for micronutrient efficient crops, and diversification of cropping systems. CGIAR's Harvest Plus programme is one of the efforts being undertaken in this direction.

The final keynote presentation by Dr. Krishna B. Karki and colleagues from the Nepal Agricultural Research Council's Soil Science Division (NARC-SSD) summarised the status of soil micronutrient problems in Nepal. Visual symptoms of micronutrient deficiencies in indicator crops have been recognised for a long time. Studies of soil micronutrients have been undertaken in the country since 1971. There was a big step forward when Nepal was 
included in Mikko Sillanpää's Global Assessment of Micronutrients (FAO 1982), which raised awareness among Nepalese researchers of the scale of micronutrient deficiencies. In the high Himalayan region, available zinc and manganese is relatively abundant, and only boron presents a problem to agriculture. In the western and central hills, boron, zinc, manganese, and copper are frequently low. However, some studies show that soil content of iron, zinc, copper, and manganese can be high in the Kathmandu Valley owing to the use of city waste as compost. Trials in the Valley have shown a positive response to application of boron and molybdenum. Boron and zinc are low in the inner Terai (Chitwan), and boron, zinc, manganese, and copper, elsewhere in the Terai. There has been less mapping of molybdenum status than of other elements, but deficiency in this element is a common reason for reduced yields of vegetables and legumes. Boron deficiency is very widespread and strikes wheat, vegetables and fruit crops. Zinc deficiency is a major problem in rice cultivation.

\section{Human nutrition}

According to Chandyo, in 2001 the World Health Organisation finally recognised the efficacy of zinc supplementation in the treatment of acute diarrhoea. In a double blind intervention trial from Bhaktapur in the Kathmandu Valley, zinc supplementation shortened the duration of acute diarrhoea by $19.26 \%$ and reduced the risk of prolonged diarrhoea by $43.47 \%$. Zinc intervention has potential impacts on other infectious diseases as well. Preliminary findings from studies in Bhaktapur on the effects of zinc supplementation on pneumonia were promising but more research is needed. Valentiner-Branth (not in this publication) has discussed the reasons for these effects. Zinc deficiency is known to affect development of the immune system, but he hypothesised that zinc also has a pharmacological effect on infection.

Attaluri and Ilangantileke presented research from the International Potato Center (CIP) on vitamin A rich orange fleshed sweet potatoes which have been bred in order to reduce vitamin A deficiency. Because sweet potatoes are a common food item in some areas in Asia, the improved varieties have a potential to improve nutrition without dietary changes or altered cropping patterns.

\section{Problems in agriculture}

Rai and colleagues presented the results of studies on the spatial variation of soil zinc status in Rupandehi district, Nepal. The area has low to medium zinc content in the soils (0.013. 1.402 ppm DTPA extractable), making zinc deficiency the most widespread micronutrient disorder in the district. It was not possible to establish statistically significant associations with other soil variables. The study showed the usefulness of GIS and geo-statistics for analysing soil status.

Narwal et al. presented findings on the status of micronutrients in soils in different agroclimatic zones in Haryana, India. Imbalanced fertilisation with macronutrients together with intensive agriculture has led to depletion of micronutrients, especially of zinc, iron and manganese. The copper status was not critical. Overall, soils in the southwestern zone were more deficient in micronutrients than soils in the northeastern zone. In the southwestern zone, between 32 and $88 \%$ of the soils sampled in different districts were deficient in zinc, in the northeastern zone it varied from 30 to $78 \%$. Although increasingly farmers are using 
zinc and other micronutrient fertilisers, the overall balance between supply and crop removal losses was negative for all micronutrients. The increase in production has led to larger removals by crops. Between 1966/67 and 2001/02, removal of zinc increased from 20 to 80 grams per hectare. Thus Haryana is in urgent need of improved nutrient balance management.

Takkar and Jalali presented a review of soil micronutrient problems from India. In most zones, zinc deficiency is a major problem, affecting grain crops as well as pulses and fruit orchards. Deficiencies of copper, iron, and manganese are less frequent. Intensification worsens the status: in Uttar Pradesh, zinc in foothill soils went down from $2.77 \mathrm{ppm}$ to $<1$ ppm over 12 years of rice-wheat-cowpea cultivation. Boron deficiency is also widespread in many soils. Applications of micronutrients have shown good results in many places in India.

Bhatta et al. examined a number of genotypes of wheat for susceptibility to sterility (no grain formation). Grain sterility in wheat in Nepal (and neighbouring countries) is largely induced by boron deficiency, although other environmental factors also play a role. Sterility may at times reach $100 \%$, and soil application has produced very significant results. The susceptibility is largely genetically controlled. A screening of 200 genotypes in 2002/03 and 317 genotypes in 2003/04 showed sterility rates varying from 1 to 100\%, typically either very low or very high. Application of boron in control fields indicated that deficiency of this element was the main cause.

Shrestha et al. tested the effects of supplements of selenium on goats in Nepal and observed substantially increased fertility and reduced kidding interval, reduced kid mortality, and less disease occurrence in the flock. This highlights two issues: that livestock in Nepal is also affected by micronutrient deficiencies, and that there is selenium deficiency in the environment in Nepal. This may also have implications for human health. Both issues are in need of further research.

Sapkota and Andersen studied a peri-urban farming area in the Kathmandu Valley where traditional farming has been replaced by highly intensive horticulture. The effect of commercialisation has been that the farmers have improved their soil nutrient management substantially, using compost, purchased chicken manure, and chemical fertilisers, as well as micronutrient fertilisers. The soils were found to be acid and deficient in boron, but otherwise to have good nutritional status. However, farmers use the nutrients in a haphazard manner without soil testing and, and their knowledge of plant nutrition is not sufficient to deal with micronutrient problems in a cost-effective manner.

\section{The social science context}

Andersen discussed the gap between local knowledge systems and scientific knowledge, and suggested that addressing the knowledge gap on micronutrients was a major strategic problem. Although some traditional farming practices are having effects, local knowledge does not contain concepts that are able to comprehend micronutrient issues. On the other hand, the present traditions in scientific research and agricultural extension have developed little information in terms of strategies and recommendations that has relevance to marginal farmers. Mapping of soil nutrients is a prerequisite for issuing recommendations: uniform deficiencies can be addressed with blanket recommendations, but spatial variations require 
other extension models. Andersen suggested that alternative pathways of knowledge dissemination should be addressed, including provision of knowledge on visual symptoms and micronutrient disorders to fertiliser traders, farmers, and schools.

Manandhar and Khanal gave an overview of the legal system for quality control of fertilisers in Nepal. After deregulation of the fertiliser trade in 1997, the government issued a Fertiliser (Control) Order. In accordance with the Guidelines issued in 1999, 75 fertiliser inspectors have been appointed under the District Agriculture Development Offices (DADO). Soil testing laboratories have been authorised, and fertiliser test kits developed for testing adulteration of fertilisers, which is a major problem. So far, 27 inorganic fertilisers have been approved and the rules for specification of major element fertilisers are well developed. However, there is as yet no system for specification or control of micronutrient fertilisers, and these products are largely applied haphazardly by farmers.

\section{Analysis using soil applications}

Srivastava et al. showed how boron is a severely limiting factor for grain legume production in the inner Terai. Omission experiments at a field station had shown that boron and molybdenum were major limiting factors for chickpea. On-farm trials were conducted to determine the effects of different levels of micronutrient supplies to chickpea, lentil and mustard. The maximum yield appeared to be reached with applications of $0.5 \mathrm{~kg} / \mathrm{ha}$ boron; more than $3 \mathrm{~kg} /$ ha appeared to approach the toxic range. The yield response of lentils was about tenfold. There was also a significant response to zinc applications of $2 \mathrm{~kg} / \mathrm{ha}$, but a decrease when the amount was increased to $4 \mathrm{~kg} / \mathrm{ha}$. The small amount of boron needed suggests that field application of this element could be economically viable and relevant for resource poor farmers.

Sherchan et al. carried out a study at Rampur, Chitwan, to identify the limiting micronutrients and their effect on maize productivity and quality. The study used omission of boron, zinc, sulphur, manganese, iron, copper, and molybdenum, compared to control fields with full 120:60:40 NPK treatment, and without organic manure and chemical fertilisers. Soil and plant samples were analysed. Although boron is a known problem in the area, there was no significant effect of boron on maize. Likewise, although soil and plant zinc concentrations were below normal critical values, zinc did not have any significant impact on yields, but there was a significant correlation between soil content of zinc and manganese, and the concentration in leaves.

Shivay \& Kumar reported in a review that the extent of zinc deficiency in Indian soils is almost $50 \%$, and that it is increasing. In their experiments, they studied interactions between phosphorous and zinc in aromatic rice. Both elements significantly influenced grain, straw and biological yields, and harvest index. The yields increased significantly up to applications of $40 \mathrm{~kg} / \mathrm{ha} \mathrm{P}_{2} \mathrm{O}_{5}$. The optimum dose of zinc was found to be $5 \mathrm{~kg} / \mathrm{ha} \mathrm{Zn}$, whereas lower applications did not have any significant impact on yield. Although it is known from the literature that interactions can occur between zinc and phosphorous, no significant interaction effects were found at the moderate levels studied.

Adhikary et al. described the results of a study of different micronutrients on grain production of toria (Brassica campestris) in Chitwan under farmers' field conditions. Soil 
application of a combination of boron, zinc, and sulphur produced the highest grain yield, $1115 \mathrm{~kg} / \mathrm{ha}$ compared to $605 \mathrm{~kg} / \mathrm{ha}$ in a control field. However, considerable differences were found when a research field was brought into comparison, indicating that soil type plays an important role in response to fertilisation.

\section{Other agricultural methods}

Soil applications will inevitably incur losses. As commercial micronutrients are often costly, it is important to consider other methods, especially for resource poor farmers.

Bodruzzaman et al. studied the impact of micronutrient enrichment of seeds of wheat and rice in Bangladesh. Salts of zinc, molybdenum, nickel, copper, manganese, and boron were applied to crops in on-farm trials by foliar spraying. The enriched seeds showed substantially increased yield, wheat by $25 \%$ in twelve of forty-seven trials, and rice by $22 \%$ in twelve of seventeen trials. The authors believe that some of the effect was the result of increased resistance to disease. The study suggests that micronutrient enrichment of seeds can improve yields of wheat and rice in areas where soil testing is unavailable. However, the researchers were cautious about recommending foliar spraying of micronutrients because it is laborious and not necessarily practical for resource poor farmers.

In a study on alkaline soils from the North West Frontier zone in Pakistan, Harris et al. tested priming (soaking seeds in water) of wheat and chickpea with solutions of zinc sulphate. The safe, optimum solution for wheat was found to be $0.4 \%$ zinc, which led to a mean increase in yield of $615 \mathrm{~kg} / \mathrm{ha}$ compared to non-primed seeds. For chickpea, the safe, optimum concentration was $0.05 \%$ zinc, which gave a mean yield increase of $48 \%$ over non-primed seeds. The benefit:cost ratio for priming wheat with zinc was calculated to be about 360, of which 160 could be contributed to zinc alone and the remainder to the effect of priming in water. This compares to a benefit:cost ratio of 8 for soil application of zinc. The benefit:cost ratio for priming chickpea with zinc was about 1500, of which 750 was a response to zinc. Thus, it appears that seed priming is a much more appropriate method for resource poor farmers than soil application.

In another priming study, Johansen et al. studied micronutrient problems in chickpeas grown on acid soils in the High Barind Tract, Bangladesh. Molybdenum was found to be the only limiting micronutrient, giving a yield response of $73 \%$. Trials were held to test the effects of soil application of molybdenum and Rhizobium inoculation. In addition, trials were carried out with seed priming in water containing molybdenum and Rhizobium. It was found that all treatments gave substantial increases compared to control fields. Adding molybdenum and Rhizobium to priming water reduced the amount of molybdenum needed, and had several features which suggest that it is a favourable method for resource poor farmers. Feasibility studies are planned to determine whether this is really the case.

Chaudary and Narwal presented data on the effects of long-term application of farmyard manure (FYM) on soil micronutrient status in a pearl millet-wheat cropping system in Hisar, India. FYM was applied at rates of 15, 30, and 45 tonnes per hectare; the soils contained significantly higher amounts of all micronutrients than a control field. The content of micronutrients correlated significantly with soil organic matter, with the highest increase in the upper soil layers and with winter application of FYM. 
Regmi et al. focused on experiences from research into integrated plant nutrient management systems (IPNS) in the mid hills. IPNS aims at enhancing local knowledge to develop holistic soil management at farm level. Organisation of farmer-field schools is an important element. A long list of methods includes improved FYM production, legume integration, and avoiding excessive use of chemical fertiliser. Experiments in farmers' fields showed that application of boron and molybdenum had a positive impact on cauliflower production, and applications of boron on wheat. Maize responded to zinc application. Many of the techniques gave positive results, but there was a need for location specific analysis of problems, as well as for institutions for building and maintaining knowledge.

Khanal et al. studied various methods of micronutrient supplementation to a number of crops in hill areas and the Terai plains in Nepal. Priming water, soil applications, and foliar sprays of cattle urine and stinging nettle extract were compared. The soils were generally constrained by boron and zinc, and molybdenum affected yields of pulses. All treatments gave positive yield results compared to controls, indicating that there is vast scope for developing and testing different methods of micronutrient applications based on locally available resources for resource poor farmers. 


\section{Acronyms and Abbreviations}

\begin{tabular}{|c|c|}
\hline $\begin{array}{l}\text { AAS } \\
\text { AIC }\end{array}$ & $\begin{array}{l}\text { atomic absorption spectrophotometer } \\
\text { Agricultural Inputs Corporation }\end{array}$ \\
\hline BINA & Bangladesh Institute of Nuclear Agriculture \\
\hline BpLB & Bipolaris leaf blight \\
\hline CEC & cation exchange capacity \\
\hline CGIAR & Consultative Group on International Agricultural Research \\
\hline CIAT & International Center for Tropical Agriculture \\
\hline CIMMYT & International Maize and Wheat Improvement Center \\
\hline CIP & International Potato Center \\
\hline $\mathrm{cv}$ & co-efficient of variation \\
\hline DADO & district agricultural development office \\
\hline DAS & days after sowing \\
\hline FAO & Food and Agriculture Organization (UN) \\
\hline FYM & farmyard manure \\
\hline GLRP & Grain Legumes Research Programme \\
\hline GPS & global positioning system \\
\hline GR & Green Revolution \\
\hline GRW & grain weight \\
\hline ha & hectare \\
\hline HBT & High Barind Tract (Bangladesh) \\
\hline HMGN & His Majesty's Government of Nepal \\
\hline $\mathrm{HP}$ & Himachal Pradesh \\
\hline IAAS & Institute of Agriculture and Animal Sciences (Nepal) \\
\hline ICARDA & International Centre for Agricultural Research in the Dry Areas \\
\hline ICP & inductively-coupled plasma \\
\hline ICRISAT & International Crop Research Institute for the Semi-Arid Tropics \\
\hline IFA & International Fertilizer Industry Association \\
\hline |FPRI & International Food Policy Research Institute \\
\hline IITA & International Institute of Tropical Agriculture \\
\hline IPNM & integrated plant nutrient management \\
\hline IPNS & integrated plant nutrient system \\
\hline |RRI & International Rice Research Institute \\
\hline $\begin{array}{l}\text { ISNRMP } \\
\text { IU }\end{array}$ & $\begin{array}{l}\text { Indo Swiss Natural Resource Management Programme } \\
\text { international unit }\end{array}$ \\
\hline JRP & Jute Research Programme \\
\hline JT & junior technician \\
\hline JTA & junior technical assistant \\
\hline
\end{tabular}




\begin{tabular}{|c|c|}
\hline LARC & Lumle Agricultural Research Centre \\
\hline LBW & low birth weight \\
\hline LKS & local knowledge system \\
\hline LSD & least square deviation \\
\hline MOA & Ministry of Agriculture \\
\hline MPN & most probable number \\
\hline NARC & Nepal Agricultural Research Council \\
\hline NWRP & National Wheat Research Programme \\
\hline NY & New York \\
\hline OFSP & orange-fleshed sweet potato \\
\hline OM & organic matter \\
\hline $\begin{array}{l}\text { PAC } \\
\text { ppm }\end{array}$ & $\begin{array}{l}\text { Pakhribas Agricultural Research Centre } \\
\text { parts per million }\end{array}$ \\
\hline PPR & 'pestes des petits ruminantes' (diseases of small ruminants) \\
\hline PRDF & Participatory Rural Developmental Foundation \\
\hline PVS & participatory variety selection \\
\hline PZMR & phytate-zinc molar ratio \\
\hline RARS & Rampur Agricultural Research Station \\
\hline $\mathrm{RCB}$ & randomised complete block \\
\hline sed & standard error deviation \\
\hline SKS & scientific knowledge system \\
\hline SOC & soil organic carbon \\
\hline SOM & soil organic manure \\
\hline SRDI & Soil Resources Development Institute (Shyampur) \\
\hline SSD & Soil Science Division \\
\hline STSS & Soil Testing and Service Section \\
\hline STV & stover yield \\
\hline SWCA & South, West and Central Asia \\
\hline THW & thousand-grain weight \\
\hline TOT & transfer-of-technology \\
\hline UNICEF & United Nations Children's Emergency Fund \\
\hline UP & Uttar Pradesh \\
\hline USAID & US Agency for International Development \\
\hline USDA & United States Department of Agriculture \\
\hline USDA-ARS & United States Department of Agriculture, Agricultural Research Service \\
\hline VAD & vitamin A deficiency \\
\hline WHO & World Health Organization \\
\hline WORLP & Western Orissa Rural Livelihood Project \\
\hline
\end{tabular}




\section{Chemicals}

\section{AAAC-EDTA}

$A B$

$A C C$

Al

As

B

C

$\mathrm{Cd}$

$\mathrm{Cl}$

Co

$\mathrm{Cr}$

$\mathrm{Cu}$

DAP

DTPA

$\mathrm{F}$

$\mathrm{Fe}$

$\mathrm{Hg}$

HNPV

I

K

$\mathrm{Li}$

$\mathrm{Mg}$

$\mathrm{Mn}$

Mo

MOP

$\mathrm{N}$

$\mathrm{Na}$

$\mathrm{Ni}$

$P$

$\mathrm{P}_{2} \mathrm{O}_{5}$

$\mathrm{Pb}$

PYR

$S$

$\mathrm{Se}$

$\mathrm{Si}$

Sn

TSP

$\checkmark$

Zn acid ammonium acetate - ethylenediaminetetracetic acid

ammonium bicarbonate

accumulated flow

aluminium

arsenic

boron

carbon

cadmium

chlorine

cobalt

chromium

copper

diammonium phosphate

diethylenetriaminepentaacetic acid

fluorine

iron

mercury

Helicoverpa nuclear polyhedrosis virus

iodine

potassium

lithium

magnesium

manganese

molybdenum

muriate of potassium

nitrogen

sodium

nickel

phosphorous

phosphorous pentoxide

lead

pyrene

sulphur

selenium

silicon

stannous (tin)

triple superphosphate

vanadium

zinc

Note: In Nepal, the calendar year is based on the Vikram Sambhat system and runs from mid April to mid-April. Yearly data are presented in the form '2004/05' meaning the calendar year from mid April 2004 to mid April 2005. In some cases, particularly data from India, the form '2004/05' refers to a cropping year - from late spring/early summer to late spring/early summer. 


\title{
Glossary
}

\author{
aqua regia also known as royal water, a mixture of hydrochloric and nitric acids \\ bagar khet sandy/gravelly lowland \\ bari \\ bhed \\ rainfed upland (usually terraces) \\ shallow lake \\ kandi \\ high altitude soils \\ karewa \\ Hapludalfs soil type \\ kharif \\ summer (rainy) season \\ khet \\ irrigated (flooded) lowland used to grow rice \\ kriged \\ an indicator, kriging is a geostatistical method which estimates the \\ distribution of grades within a block \\ $\mathrm{pH}$ \\ derived from the German word, 'potenz hydrogen' meaning power of \\ hydrogen. The $\mathrm{pH}$ of a solution is related to its hydrogen ion \\ concentration and indicates the acidity /alkalinity. \\ rabi \\ winter (dry) season \\ sim khet \\ wet lowland \\ toria \\ rapeseed/oilseed \\ upazilla \\ A rural administrative subdivision of a district in Bangladesh \\ zizufus \\ jujube/ Chinese date
}




\section{Contents}

Foreword

Editor's Preface

Acknowledgements

Executive Summary

Acronyms and Abbreviations

Glossary

\section{Keynote Presentations}

Dietary Strategies to Enhance Micronutrient Adequacy: Experiences in

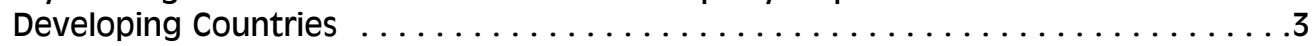

- R.S. Gibson

Harvesting Health: Agricultural Linkages for Improving Human Nutrition . . . . . . . .99

- R.M. Welch

Distribution of Micronutrients Available to Plants in Different Ecological

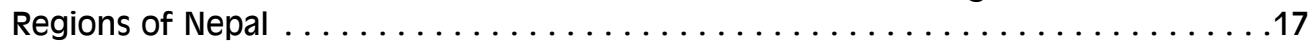

- K.B. Karki, J.K. Tuladhar, R. Uprety and S.L. Maskey

\section{Session 1 - Human Nutrition and Health ...............}

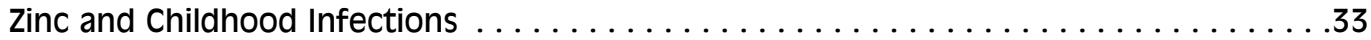

- R.K. Chandyo

Growing orange-fleshed sweet potatoes to combat Vitamin A deficiency in Eastern India: experience of the International Potato Center (CIP) $\ldots \ldots \ldots \ldots \ldots \ldots \ldots \ldots$

- S. Attaluriand S. llangantileke

Supplementation of Selenium: A Strategy to Increase Fertility in Goats . . . . . . . .43

- S.P. Shrestha, C. Rymer, M.L. Jayaswal, N. Lama, K.P. Neupane and V.N. Jha

\section{Session 2 - Mapping and Soll Micronutrient Status . . . . . . . 47}

Mapping Spatial Zinc Distribution in Rupandehi District, Nepal $\ldots \ldots \ldots \ldots \ldots . \ldots 49$

- S.K. Rai, S.P. Pandey, Y.G. Khadka, K.B. Karki and R. Uprety

Micronutrient Status in Different Agro-climatic Zones of Haryana, India . . . . . . . . .57

- R.P. Narwal, R.S. Antil, B. Singh and S.S. Dahiya

Severe Boron Deficiency limiting Grain Legumes in the Inner Terai of Nepal . . . . . 667 - S.P. Srivastava, C. Johansen, R.K. Neupane, and M. Joshi

\section{Session 3 - Soil Nutrient Management ...............77}

Micronutrient Status of Soil and Response to Long-term Application of

Farmyard Manure (FYM)

- M. Chaudhary and R.P. Narwal

Building Contextual Knowledge: the Interface between Local and Scientific

Knowledge

- $P$. Andersen 
Managing Soil Fertility Problems of Marginal Agricultural Lands through Integrated Plant Nutrient Management Systems: Experiences from the Hills of Nepal . . . .109 - B.D. Regmi, C. Poudel, B.P Tripathi, S. Schulz and B.K. Dhital

Effect of Micronutrient Loading, Soil Application, and Foliar Sprays of Organic Extracts on Grain Legumes and Vegetable Crops under Marginal Farmers' Conditions in Nepal

- N. Khanal, K.D. Joshi, D. Harris and S.P. Chand

Soil Fertility Problems and Strategies to Reduce Them in the Himalayan Region of India

- P.N. Takkar and V.K. Jalali

Alleviating Micronutrient Deficiencies in Alkaline Soils of the North West Frontier Province of Pakistan: On-farm Seed Priming with Zinc in Wheat and Chickpea . . 143 - D. Harris, A. Rashid, M. Arif and M.Yunas

Commercial Horticulture Farming and its Effect on Soil Fertility: A Case Study from Peri-urban Agriculture in the Kathmandu Valley

$-K$. Sapkota and P. Andersen

\section{Session 4 - Soll and Plant Interactions}

Effect of Micronutrients on Production of Maize (Zea Mays L.) in the

Acid Soils of Chitwan Valley

- D.P. Sherchan, R. Upreti and S.L. Maskey

Enhancing Effect of Micronutrients on the Grain Production of Toria

(Brassica Campestris Duth. Var. Toria) in Chitwan Valley

- B.H. Adhikary, D.P. Sherchan and D.D. Neupane

Increasing Wheat and Rice Productivity in the Sub-Tropics Using Micronutrient

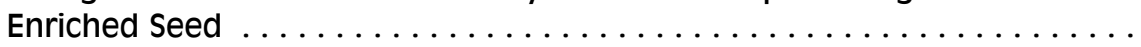

- M. Bodruzzaman, J.G. Lauren, J.M. Duxbury, M.A. Sadat, R.M. Welch, N. E-Elahi and C.A. Meisner

Effect of Phosphorous and Zinc Fertilisation on the Productivity of

Transplanted Aromatic Rice

$-Y . S$. Shivay and D. Kumar

Molybdenum Response of Chickpea in the High Barind Tract (HBT) of

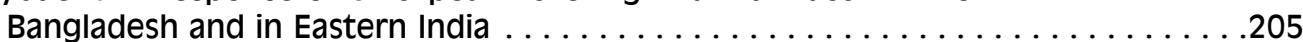

- C. Johansen, A.M. Musa, J.V.D.K. Kumar Rao, D. Harris, M.Y. Ali and J.G. Lauren

Wheat Sterility Induced by Boron Deficiency in Nepal

- M.R. Bhatta, G.O. Ferrara, E. Duveiller and S. Justice

\section{Annexes}


